\title{
An international perspective on the management of glioblastoma
}

\author{
Rimas V. Lukas ${ }^{1,2}$, Evangelia D. Razis ${ }^{3}$, Jason T. Huse ${ }^{4}$ \\ ${ }^{1}$ Department of Neurology, Northwestern University, Chicago, IL, USA; ${ }^{2}$ Lou \& Jean Malnati Brain Tumor Institute, Northwestern University, \\ Chicago, IL, USA; ${ }^{3}$ rd Department of Oncology, Hygeia Hospital, Marousi, Greece; ${ }^{4}$ Departments of Pathology and Translational Molecular \\ Pathoogy, University of Texas MD Anderson Cancer Center, Houston, TX, USA \\ Correspondence to: Rimas V. Lukas, MD. Department of Neurology, Northwestern University, 710 N. Lake Shore Drive, Abbott Hall 1114, Chicago, \\ IL 60611, USA. Email: rimas.lukas@nm.org.
}

Submitted Aug 04, 2021. Accepted for publication Aug 13, 2021.

doi: $10.21037 / \mathrm{cco}-21-107$

View this article at: https://dx.doi.org/10.21037/cco-21-107

The world is progressively more interconnected. Events in one location exhibit impacts across the globe. Knowledge gleaned and developed in one place can spread diffusely. Collaboration across geographic locations has become increasingly important for the advancement of science. These points hold true for the field of neuro-oncology. This special series on glioblastoma (GBM), in addition to overviewing scientific advances and future directions for therapeutic investigations, will also provide a broad international perspective on clinical management. We hope that these insights will clarify ongoing successes as well as obstacles that will need to be overcome on a countryspecific level. In assembling this series, a diverse range of perspectives was actively sought, although we acknowledge that it is impossible to be completely comprehensive in such an undertaking.

As neuro-oncology is a relatively narrow field, it is obvious that international collaboration is necessary in order to achieve the breadth of knowledge, disciplines and expertise demanded by the difficult diseases in question. Multiple ongoing efforts to facilitate international collaboration and knowledge dissemination in neurooncology extend beyond organically developed research collaborations and are oftentimes framed within organizations and societies dedicated to the field. One such long-standing example is the International Brain Tumor Alliance (IBTA) (1) based in the United Kingdom, which has been successful in raising awareness and advocating for neuro-oncology research funding. These achievements have stemmed, at least in part, from effective collaboration with other advocacy groups, philanthropic and governmental organizations, pharmaceutical companies, clinicians, researchers, patients, and families. This type of multilateral effort serves as a model for how positive effects can be amplified. Another example of international collaboration can be seen within the context of professional societies. The American Society of Clinical Oncology (ASCO) (2) has facilitated knowledge exchange through a range of venues including its annual meeting and its virtual mentor program. The Society for Neuro-Oncology (SNO) $(3,4)$, via its International Outreach Committee (5), has a similar mentorship program in development, has provided seed funding for neuro-oncology meetings in the developing world, and has been supporting international travel scholarships to its annual meeting. As with the IBTA, SNO has been collaborating with other regional neurooncology societies including the European Association for Neuro-oncology (EANO), the Asian Society for NeuroOncology (ASNO), Society for Neuro-Oncology Latin America (SNOLA), and the Society for Neuro-Oncology in Sub-Saharan Africa (SNOSSA), among others. The World Federation of Neuro-Oncology Societies (WFNOS) was founded to provide a unified partnership across these various societies (6). It is anticipated that these relationships will develop further and strengthen over time.

In this special series we provide perspectives on the management of GBM from Nigeria (7), Australia (8), Lithuania (9), and Mexico (10). Epidemiologic knowledge, clinical management within the context of the health care system, and key research endeavors are covered. Again, while this does not provide a comprehensive international overview our hope is that these articles serve as distinct 
windows that each inform a global perspective.

\section{Acknowledgments}

Funding: None.

\section{Footnote}

Provenance and Peer Review: This article was commissioned by the editorial office, Chinese Clinical Oncology for the series "The Evolving Landscape of the Management of Glioblastoma". The article did not undergo external peer review.

Conflicts of Interest: All authors have completed the ICMJE uniform disclosure form (available at http://dx.doi. org/10.21037/cco-21-107). The series "The Evolving Landscape of the Management of Glioblastoma" was commissioned by the editorial office without any funding or sponsorship. Dr. RVL served as the unpaid Guest Editor of the series, and serves as an unpaid editorial board member of Chinese Clinical Oncology from Aug 2019 to Jul 2021. Dr. RVL reports research support from NIH P50CA221747, BrainUp 2136, and BMS (drug only); honoraria from serving on a scientific advisory board and speakers' bureau for Novocure; and honoraria for medical editing for EBSCO Publishing and Medlink Neurology and for the creation and presentation of CME board review content for American Physician Institute. Dr. EDR reports Research Funding-Novartis, Paraxel, Tesaro; Consulting or Advisory Role - AstraZeneca, Bristol Mayer Squibb; Bristol Mayer Squibb - Honoraria; and Travel, accommodations expenses - Leo Pharma, Roche, Genekor, Merck, Ipsen, Sanofi, Novartis, Pfizer, Bristol Mayer Squibb, Genesis Pharmaceuticals. The authors have no other conflicts of interest to declare.

Ethical Statement: The authors are accountable for all aspects of the work in ensuring that questions related to the accuracy or integrity of any part of the work are

Cite this article as: Lukas RV, Razis ED, Huse JT. An international perspective on the management of glioblastoma. Chin Clin Oncol 2021;10(4):40. doi: 10.21037/cco-21-107 appropriately investigated and resolved.

Open Access Statement: This is an Open Access article distributed in accordance with the Creative Commons Attribution-NonCommercial-NoDerivs 4.0 International License (CC BY-NC-ND 4.0), which permits the noncommercial replication and distribution of the article with the strict proviso that no changes or edits are made and the original work is properly cited (including links to both the formal publication through the relevant DOI and the license). See: https://creativecommons.org/licenses/by-nc-nd/4.0/.

\section{References}

1. Available online: https://theibta.org/ (Accessed 1/4/2021).

2. Available online: https://www.asco.org/ (Accessed 1/4/2021).

3. Available online: https://www.soc-neuro-onc.org/ (Accessed 1/4/2021).

4. Balogun J, Haynes C, Lwin Z, et al. SNO 25th anniversary history series: Providing a global platform for communication and exchange in neuro-oncology. Neuro Oncol 2020;22:1551-2.

5. Available online: https://www.soc-neuro-onc.org/WEB/ Resources/International_Outreach/WEB/Resources_ Content/International_Outreach.aspx?hkey=a1a9fec22b18-4942-b295-ff035608f9a1 (Accessed 1/4/2021).

6. Available online: https://wfneurology.org/ (Accessed 8/5/2021).

7. Balogun JA, Adekanmbi AA. Management of glioblastoma: a perspective from Nigeria. Chin Clin Oncol 2021;10:43.

8. Sim HW, Nowak AK, Lwin Z, et al. Management of glioblastoma: an Australian perspective. Chin Clin Oncol 2021;10:42.

9. Bunevicius A, Usinskiene J, Buneviciene I, et al. Management of glioblastoma: a perspective from Lithuania. Chin Clin Oncol 2021;10:41.

10. Moreno-Jiménez S, Alegría-Loyola MA, Sonabend AM, et al. Management of glioblastoma: a perspective from Mexico. Chin Clin Oncol 2021;10:44. 